\title{
Allemagne. Quelques réflexions sur la relation entre pédagogie et économie
}

Études de cas

Hermann Avenarius

\section{OpenEdition}

\section{Journals}

Édition électronique

URL : https://journals.openedition.org/ries/1344

DOI : 10.4000/ries. 1344

ISSN : 2261-4265

\section{Éditeur}

France Education international

Édition imprimée

Date de publication : 1 décembre 2005

Pagination : 125-127

ISSN : 1254-4590

Référence électronique

Hermann Avenarius, «Allemagne. Quelques réflexions sur la relation entre pédagogie et économie », Revue internationale d'éducation de Sèvres [En ligne], 40 | décembre 2005, mis en ligne le 17 novembre 2011, consulté le 07 juillet 2021. URL : http://journals.openedition.org/ries/1344 ; DOI : https://doi.org/ 10.4000/ries. 1344

Ce document a été généré automatiquement le 7 juillet 2021.

(c) Tous droits réservés 


\title{
Allemagne. Quelques réflexions sur la relation entre pédagogie et économie
}

\author{
Études de cas
}

\section{Hermann Avenarius}

1 Dans les universités allemandes, la pédagogie constitue une discipline essentiellement philosophique depuis l'époque de l'idéalisme. En revanche, la réalité de l'enseignement n'a longtemps pas rencontré l'intérêt des scientifiques. La question de savoir comment organiser, réglementer, administrer et financer les établissements scolaires et le système d'enseignement est restée, encore bien des années après la fin de la Seconde Guerre mondiale, de la seule compétence de l'appareil administratif du domaine éducatif.

2 On ne s'étonnera donc pas d'avoir vu une conception traditionnelle, empreinte de néohumanisme, résister violemment à l'apparition d'approches économiques dans son champ. Le questionnement, pertinent d'un point de vue d'économiste, de l'efficacité dans l'utilisation des ressources, du rapport entre coûts et bénéfices était perçu comme incompatible avec la spécificité de la pédagogie.

3 Ce n'est qu'à partir des années soixante du siècle dernier qu'on a assisté provisoirement à un changement de paradigme. En 1964, le pédagogue Georg Picht réclama, au nom de ce qu'il nommait la "catastrophe éducative ", une augmentation massive des élèves passant le baccalauréat, condition indispensable à ses yeux pour assurer la compétitivité de l'économie allemande. L'éducation et la formation devenaient dès lors un investissement pour développer le capital humain de la société. En exploitant le potentiel des compétences, il devenait aussi possible de favoriser l'égalité des chances entre les individus. Grâce à l'appui de l'économie de l'éducation et à sa conception du capital humain, la politique éducative s'avéra en mesure de mobiliser d'importantes ressources financières afin de développer le système éducatif.

4 Cependant, un renversement de tendance apparut dès la fin des années soixante. Les budgets publics étant soutenus par une conjoncture économique favorable et le secteur 
éducatif bénéficiant entre temps d'un statut prioritaire incontesté dans l'allocation des moyens, toute argumentation de type économique en faveur de leur augmentation devenait superflue. Dès lors qu'au milieu des années soixante-dix, l'optimisme de la gouvernabilité politique et de la planification étatique en matière d'éducation commencèrent à s'effriter et prirent la dimension d'une crise, l'économie éducative perdit de son audience.

5 Le climat idéologique de cette époque renforça cette évolution en favorisant le décrochage de la politique éducative et de la pédagogie par rapport à la rationalité économique. L'économie éducative "bourgeoise " constituait un obstacle à l'esprit "progressiste» de l'époque soucieux de transformation. En tant que discipline «bourgeoise » désireuse de maintenir en place le système de domination, elle devint la cible privilégiée d'attaques venant des néo-marxistes. La visée émancipatrice visant l'instauration d'un État libéré de toute domination, qui cherchait à ce moment-là à s'étendre dans l'enseignement et dans les établissements scolaires, faisait fi du principe économique de la rareté des ressources. Le grand prestige de l'éducation au sein de la société et l'attitude généreuse de l'État en matière de financement du système éducatif contribuèrent à favoriser l'illusion de moyens disponibles à volonté. On surestima les forces de la croissance économique et les possibilités financières de l'État-Providence. On assista au retour des vieilles critiques et des vieux préjugés faisant de l'éducation et de l'économie deux mondes incompatibles; le paradigme économique en matière éducation fut de nouveau suspecté d'être un simple modèle de coûts et de bénéfices préjudiciable au système éducatif.

6 Toutefois, on constate depuis quelques années un regain d'intérêt pour les analyses économiques en matière de politique éducative et de pédagogie. Ce revirement tient en premier lieu aux profondes transformations du contexte socio-économique dans lequel se trouve le système éducatif lui-même et aux difficultés croissantes de son pilotage. Les doutes quant à la rentabilité et à la qualité de la «production éducative » de l'État ont eu pour conséquence, dans un contexte de crise financière aggravée de l'État et de prise en compte d'autres priorités sociales, que le domaine éducatif a perdu cette position autrefois privilégiée dans la répartition des fonds publics. On exige dès lors de la part des acteurs du système éducatif une plus grande prise de responsabilité dans la gestion des ressources et la prise en compte de critères de rationalité et d'efficacité dans l'utilisation des moyens. De nouvelles formes de pilotage administratif, en particulier celle élaborée aux États-Unis s'implantent aussi dans le secteur éducatif.

7 Le choc causé, il y a quelques années, par les résultats comparativement médiocres des élèves allemands à PISA, l'étude internationale de l'OCDE, a renforcé le besoin des établissements scolaires de se légitimer. Leurs résultats sont de plus en plus mesurés à l'aune de critères qui viennent de l'économie. Les notions utilisées depuis peu dans le vocabulaire de la politique et de la recherche éducative en sont la preuve. Il n'y est plus question que de «management de la qualité », de "contrôle de qualité », de «bilan de qualité de l'enseignement ", de "référentiels éducatifs ", d'" efficacité de production », de "programmation des ressources", de "budgétisation, d'«augmentation de l'efficience", de "programmation de formation centrée sur la demande», etc. L'approche économique longtemps tant décriée semble revenir en force dans la vie quotidienne des établissements scolaires sans se heurter à de grandes résistances.

8 En dépit de la préoccupation compréhensible de voir l'École passer sous la coupe d'un économisme unilatéral, les récentes évolutions fournissent une occasion réaliste de 
réconcilier pédagogie et économie. Les parents, les élèves, la politique et l'opinion publique sont en droit d'attendre de l'École qu'elle s'acquitte des tâches qui lui sont assignées. C'est dans cette mesure qu'elle doit faire preuve de qualité et rendre compte des résultats de son travail. Elle est donc soumise ainsi aux lois de la rationalité économique. Pour satisfaire à une telle exigence, elle doit toutefois être libérée des réglementations tatillonnes et disposer de suffisamment d'autonomie dans l'accomplissement de ses tâches pédagogiques, dans la gestion des moyens financiers qui lui sont alloués, dans le recrutement de son personnel pédagogique et de son administration.

Entre temps, la plupart des Länder ont voté de nouvelles lois scolaires ou, au moins, procédé à une remise à jour des lois existantes afin d'accorder plus d'autonomie aux établissements tout en les obligeant à rendre compte de la qualité de leur travail pédagogique.

INDEX

Index géographique : Allemagne

\section{AUTEUR}

\section{HERMANN AVENARIUS}

Directeur du département Financement et pilotage du système éducatif, Deutsches Institut für pädagogische Forschung (DIIPF). 